\title{
HCC-Associated Liver Transplantation - Where Are the Limits and What Are the New Regulations?
}

\author{
Christian P. Strassburg \\ Department of Medicine I, University Hospital of Bonn, Bonn, Germany
}

\author{
Keywords \\ Milan criteria - Hepatocellular carcinoma - Liver \\ transplantation - Allocation rules - Outcome prediction
}

\section{Summary}

Background: Hepatocellular carcinoma (HCC) represents an increasing health burden worldwide and a challenging disease both in terms of diagnosis and treatment. Methods: The literature available on PubMed for the period of 1990-2016 was reviewed with reference to liver allocation, HCC, liver transplantation (LT), and prediction, and the allocation rules of the German Transplant Act were reviewed. Results: Due to etiological and geographical diversity, HCC is not a homogeneous disease. In the vast majority of patients, HCC develops as a complication of chronic liver disease and cirrhosis. While most patients present with advanced HCC for which palliative strategies are the only available option, LT is the best treatment approach as it not only eliminates the diseased liver and the underlying hepatocarcinogenic mechanisms but also the cancer. The decision for LT is not an easy one to make, because outcome prediction, staging, bridging therapy, and recurrence prevention are difficult and are estimated against the background of the scarce resource of donor organs which are also competitively sought after by patients suffering from non-neoplastic terminal liver diseases, raising the issue of equality of chances in a rationed therapeutic modality. Currently, the Milan criteria are the best evaluated decision tool for LT, but many issues such as down-staging, favorable biological behavior during treatment, expansion of the morphological classification, molecular predictors, and individualized approaches are not yet satisfactorily addressed. Conclusion: In order to provide a fair and effective approach to LT in HCC, the employed allocation rules require continuous development and scientific evaluation. Recently, the allocation rules for standard exception priority according to the German Transplant Act have been revised to improve patient selection for LT in HCC.

(c) 2016 S. Karger GmbH, Freiburg

\section{Introduction}

Hepatocellular carcinoma (HCC) is a worldwide health issue associated with considerable morbidity and mortality. Globally, HCC represents the sixth most common cancer type [1], and (together with intrahepatic cholangiocarcinoma) it is the number 2 cause of cancer-related deaths [2] with increasing incidence. If left untreated, HCC is characterized by a 5 -year survival rate of $10-12 \%$ $[3,4]$.

The prevalence of HCC coincides with the geographic distribution of its accepted risk factors (table 1) which include all forms of cirrhosis, chronic hepatitis B (hepatitis B virus (HBV)) and C (hepatitis $\mathrm{C}$ virus (HCV)), non-alcoholic steatohepatitis (NASH), exposure to environmental mutagens such as aflatoxin, certain predisposing hepatic and non-hepatic diseases, as well as certain drugs [5]. Against this background, HCC prevention is, in theory, effectively achievable in many cases and should represent the primary aim of the global fight against this cancer. In this vein, the effective control of HBV and HCV infection, vaccination programs, nutritional awareness initiatives, safe food chains, and a reduction in alcohol consumption are measures with a potentially high efficacy. The advent of screening colonoscopies for the prevention of colorectal cancer-associated deaths has convincingly demonstrated the effectiveness of such preventive and surveillance strategies. The implementation of highly effective antiviral strategies in HBV and

\section{KARGER}

Fax +497614520714
๑๑ 2016 S. Karger GmbH, Freiburg 
Table 1. Risk factors and potentially protective factors for HCC

\begin{tabular}{l}
\hline Risk factors for HCC \\
Age \\
Male sex \\
Liver cirrhosis \\
Chronic HBV infection \\
Chronic HCV infection \\
Obesity \\
Type II diabetes/metabolic syndrome \\
Non-alcoholic steatohepatitis \\
Alcohol consumption \\
Hemochromatosis \\
Tyrosinemia, galactosidemia, fructosemia \\
Alpha 1-antitrypsin deficiency \\
Aflatoxin-B1 exposure \\
Cigarette smoking and cofactors \\
Genetic predisposition \\
Anabolic steroids \\
Estrogen contraceptives \\
\hline Potentially protective factors for HCC \\
HBV and HCV antiviral treatment \\
HBV vaccination \\
Physical exercise/balanced diet \\
Coffee \\
High vegetable consumption \\
Calcium/vitamin D \\
\hline
\end{tabular}

HCV treatment will further reduce the burden of HCC in the future. However, recent developments suggest that overweight and metabolic syndrome have emerged as risk factors of epidemiologically relevant proportion [6]. Based on these considerations, it is obvious that HCC is etiologically not a homogenous disease and is likely to be influenced by a plethora of molecular events driving neoplastic transformation (fig. 1) [7]. Therefore, the number of HCC cases and the potential variability of their biological behaviors constitute one of the premier challenges for medicine in the 21 st century (table 2).

\section{Treatment Options for HCC}

The screening, diagnosis, treatment, and follow-up of patients suffering from HCC require specialized hepatology centers with access to a liver transplantation (LT) program. In view of the complexity of the standard of care for these patients, it is suggested that all HCC patients least once attend such a specialized center, preferably immediately following the suspicion or diagnosis of HCC. The involved multidisciplinary specialists should include gastroenterology/hepatology, radiology, pathology, oncology, surgery, and transplantation medicine in order to aggregate their expertise and provide the patient with the best and most updated therapies [2].

In general, two treatment categories are differentiated: a potentially curative approach and a largely palliative approach (fig. 2). This distinction is largely based on the staging of the disease, which

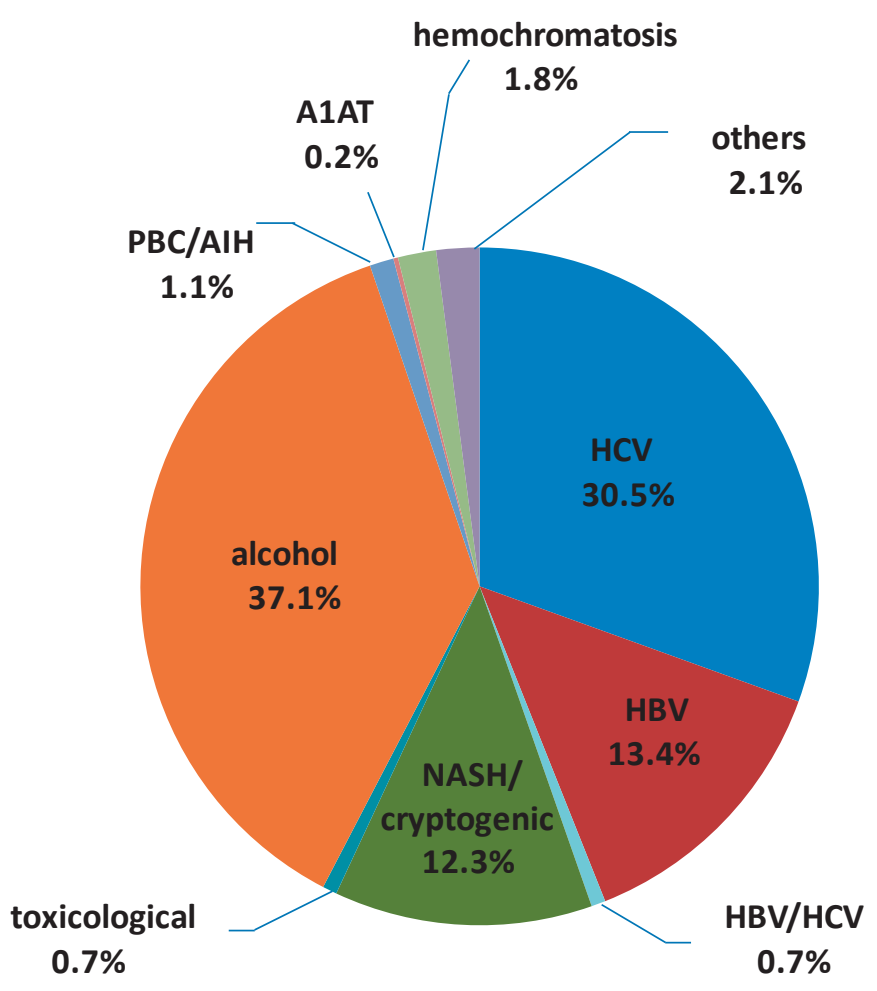

Fig. 1. Etiologies of HCC in 533 patients at the Bonn University Hospital (Bonn University Hospital Cohort). AIH = Autoimmune hepatitis; A1AT = alpha 1-antitrypsin deficiency; NASH = non-alcoholic steatohepatitis; $\mathrm{PBC}=$ primary biliary cholangitis.

requires great care and experience and often determines the course of all further interventions.

For the staging of different cancer entities, the TNM classification enjoys the widest recognition and acceptance. However, its application to HCC exhibited only a low ability to predict long-term survival [8]. For this reason, a more specific system was developed, the Barcelona Clinic Liver Cancer (BCLC) staging and treatment strategy $[9,10]$. BCLC incorporates data of the tumor and the stage of hepatic function in addition to information regarding the general clinical status of the patient [11]. Alongside the BCLC system, the TNM classification is mainly used by pathologists as a reference for studies on surgical specimens. The BCLC classification goes beyond a staging tool for HCC because it also specifies potential choices for treatment. In this classification, HCC in liver cirrhosis patients is divided into very early stage (0 stage), early stage (stage A), intermediate stage (stage B), advanced stage (stage C), and terminal stage (stage D). Moreover, it incorporates tumor burden, extent and functional stage of liver cirrhosis, liver function, biological condition of the patient, and the potential efficacy of available treatment options [12]. Therefore, most centers utilize the BCLC classification to deliver state of the art treatment and care. In order to optimize this system, a recent modification has specified stage B heterogeneity to include four subgroups, i.e. B1, B2, B3, and B4, according to the Child Pugh score, Milan criteria (MC), number and size of HCC lesions, and ECOG performance status (fig. 2). 
Table 2. Etiologies of HCC (modified according to [20])

Fig. 2. Staging system based on the BCLC classification employed in LT in HCC. (modified according to [5])

BCLC stage

\begin{tabular}{lclllll}
\hline Region & $\begin{array}{l}\text { Incidence } \\
\text { (age-adjusted) }\end{array}$ & $\begin{array}{l}\text { Male/ } \\
\text { female }\end{array}$ & $\begin{array}{l}\mathrm{HCV}, \\
\%\end{array}$ & $\begin{array}{l}\mathrm{HBV}, \\
\%\end{array}$ & $\begin{array}{l}\text { Alcohol, } \\
\%\end{array}$ & $\begin{array}{l}\text { Others, } \\
\%\end{array}$ \\
\hline Europe, all & 6.7 & 2.3 & $60-70$ & $10-15$ & 20 & 10 \\
$\quad$ South & 10.5 & 3.3 & & & & \\
$\quad$ North & 4.1 & 1.8 & & & & 10 (NASH) \\
North America & 6.8 & 2.3 & $50-60$ & 20 & 20 & 10 (aflatoxin) \\
Asia and Africa & & & 20 & 70 & 10 & \\
Asia & 21.6 & 8.2 & & & & 10 \\
China & 23.0 & 9.6 & & & & \\
Japan & 20.5 & 7.8 & 70 & $10-20$ & 10 & \\
Africa & 1.6 & 5.3 & & & & \\
World & 16.0 & 6.0 & 31 & 54 & 15 & \\
\hline
\end{tabular}

ECOG performance status (PS)

$\mathrm{PS}=0$

$\mathrm{PS}=1-2$

$\mathrm{PS} \geq 2$

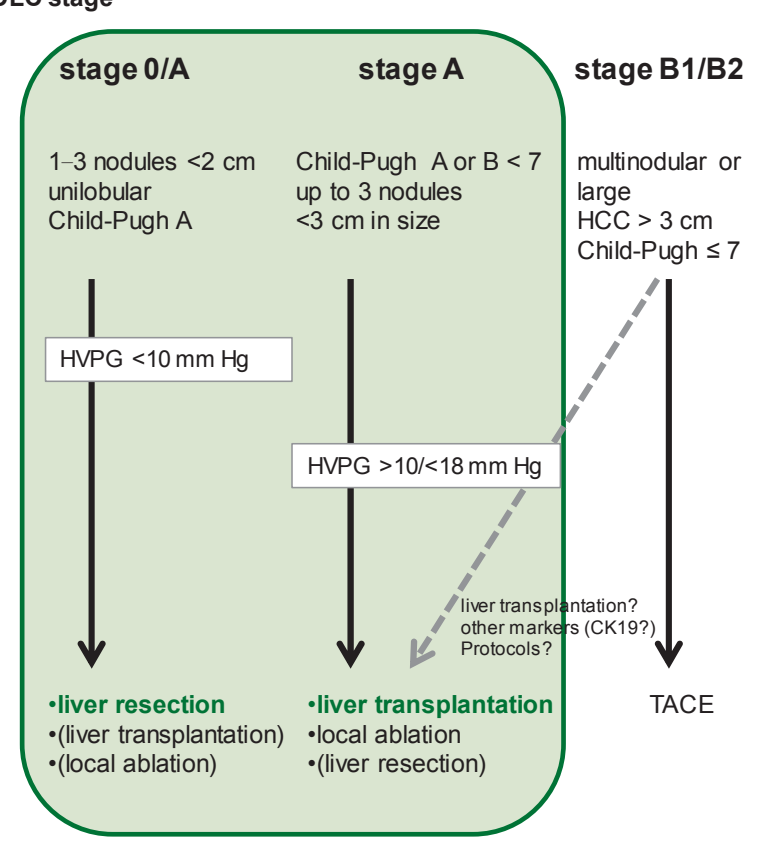

When this classification system is reviewed, it becomes obvious that only the early stages (BCLC stage A, and in some instances early B) are candidates for curative options. These include resection, ablation, and LT, each with different criteria, indications, and limitations. In a real-life assessment of HCC patients (fig. 3), only about every fourth patient is diagnosed early enough for curative therapy, three-quarters of all patients will only be candidates for palliative strategies which include local ablation (e.g. radiofrequency ablation (RFA)), transarterial chemoembolization (TACE) or radiotherapy (e.g. selective internal radiation therapy (SIRT)), and chemotherapy with the multikinase inhibitor sorafenib, or, in the terminal stages, best supportive care (which will not be discussed within the scope of this article).

Liver resection is restricted to very early stages of HCC and those patients with a suitable overall performance status and liver function. It should be considered in all early HCC $[13,14]$ by an experienced interdisciplinary team in order to prevent postoperative liver failure or deterioration. The disadvantage is a higher risk of disease recurrence, which can be as high as $50 \%$ within 3 years, most likely because the underlying process of neoplastic transformation cannot be completely eliminated when most of the patient's liver is retained. In addition, the diagnostic accuracy of identifying small lesions by imaging modalities such as ultrasound, magnetic resonance imaging (MRI), and computed tomography (CT) enhanced by specific contrast agents at the time of surgery determines whether all tumor tissue is completely resected. Compared to LT, resection offers a number of advantages because it is less costly, requires no immunosuppression, and is not dependent on a scarce donor pool. After resection as a 'bridging therapy', LT can be performed at a later point in time. The main disadvantage is the persistence of liver cirrhosis and with that one of the main drivers of hepatocarcinogenesis. Attempted resection carries a considera- 


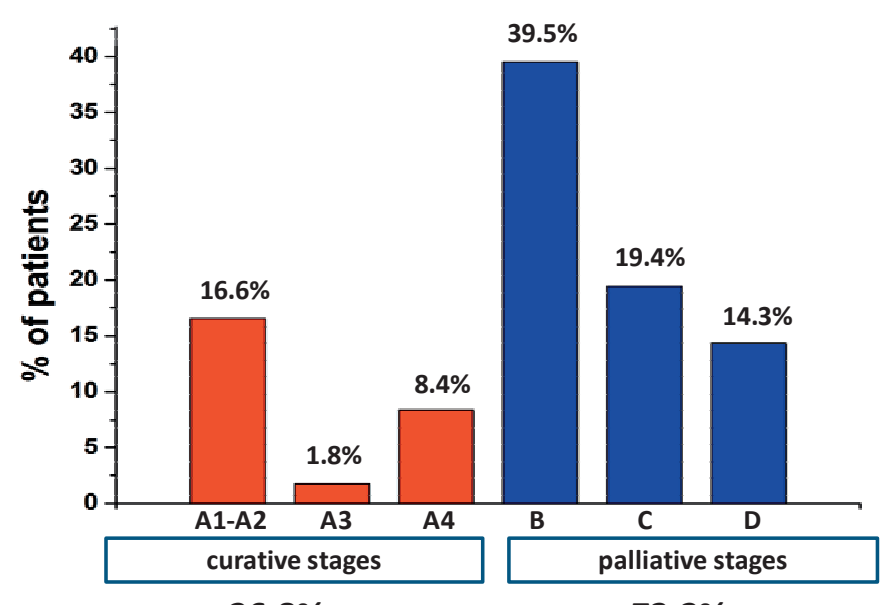

$26.8 \%$

Fig. 3. BCLC stages of 453 HCC patients seen at the Bonn University Hospital. Only about a quarter of the patients have stages allowing a curative approach.

ble risk in patients with more advanced HCC (i.e. BCLC stage C) and those patients with portal hypertension. Limited liver resection can trigger liver decompensation, gastrointestinal bleeding, and other complications, in particular when the hepatic venous pressure gradient (HVPG) exceeds $>10 \mathrm{~mm} \mathrm{Hg}$ and varices are present. Therefore, many patients who would clearly benefit from resection have to be excluded from this option [15]. In BCLC stage B, resection is likely to be safe when serum bilirubin levels are below 2 $\mathrm{mg} / \mathrm{dl}$ and ascites is absent. In carefully selected patients, the overall 5-year survival after liver resection can exceed $80 \%$, underscoring the relevance of this therapeutic option in compensated (Child Pugh A) patients with early HCC.

LT can be considered as the only truly curative approach and has become an established standard treatment option for HCC [1, 16]. If an unlimited supply of donor grafts existed, it is likely that every cirrhotic patient with HCC would be considered for LT, representing an optimal hepatologic as well as oncologic treatment option. Compared to all other treatment strategies, LT has the highest potential for cure [17-19], because it leads to the removal of the diseased liver tissue that harbors and propagates the cancer while at the same time eliminating all cancer tissue. The number of LT for HCC has increased worldwide. In Europe about one-quarter of all LT are performed because of HCC [20]. In Germany, HCC has emerged as the third most common indication for LT following alcohol- and viral hepatitis-induced liver cirrhosis [21-23].

\section{Liver Transplantation as Therapeutic Option in HCC}

The first attempts to treat HCC by LT were characterized by 5 -year recurrence rates of $32-54 \%$ and a low 5 -year survival of $40 \%$ [24-26]. The reason for these results was that patients with advanced HCC were chosen who were not suitable for hepatic resection. The lessons learned from these negative results led to the development of effective selection criteria to allow for both an im-

proved outcome for recipients and an efficient usage of the scarce donor organ pool. In 1993, Bismuth and Chiche [27] reported the best results in LT patients with $3 \mathrm{HCC}$ nodules each less than $3 \mathrm{~cm}$. A small prospective study on only 48 patients in 1996 defined criteria which are still valid and almost universally employed today, coined the MC. The selection of patients with a single HCC nodule of $5 \mathrm{~cm}$ or $3 \mathrm{HCC}$ nodules of $3 \mathrm{~cm}$ each for LT led to a 4-year survival of $75 \%$ [28].

In subsequent years, more promising results were reported showing 5-year survival rates of $70 \%$ and a recurrence rate of under $15 \%$ [29-32]. It is now almost universally established that LT is the most effective therapeutic option when patients are selected that have a single HCC lesion of $5 \mathrm{~cm}$ or $3 \mathrm{HCC}$ nodules of $3 \mathrm{~cm}$ each [20]. This is in accordance with the original MC, appears to avoid biologically aggressive tumors, and reflects the survival advantage of these patients (meta-analysis: hazard ratio 1.7). Arguments for the MC include the observation that G3 tumors and microvascular invasion are less frequent in the group meeting these criteria (hazard ratio 4.8 and 2.5) [33]. European and US registry data (European Liver Transplant Registry (ELTR), Organ Procurement and Transplantation Network (OPTN)) describe 5-year survival rates of $65-78 \%$, which does not differ significantly from other non-tumor indications for LT (65-87\%) [20]. For this reason, the MC criteria are a part of the BCLC classification of HCC. This has been adopted by the US allocation rules [34] and the German Transplant Act (TPG) regulations [35] to ensure an optimal benefit in view of the scarcity of available donor organs.

The downside of these relatively strict rules is the exclusion of patients that do not quite meet the MC, which has been met with criticism and has led to the exploration of approaches expanding the allocation criteria for LT. This activity is confronted with a number of issues: most prominently, it will expand the need for donor organs for this already large and increasing group of patients, it will provide for competition for other non-tumor indications for LT, potentially prolong waiting times and increase dropout rates, and possibly decrease intention-to-treat outcomes for LT, and, most importantly, it will have to demonstrate comparable outcomes [20,34]. Against this background, a fundamental change in allocation rules requires a sound and robust data base, which can only be achieved by prospective and multicenter, preferentially multinational, study protocols $[20,36]$.

To date, expanded criteria for LT in HCC patients have not been prospectively and independently validated except for the University of San Francisco (UCSF) criteria (single tumor of up to $6.5 \mathrm{~cm}$ or up to $3 \mathrm{HCC}$ nodules of up to $4.5 \mathrm{~cm}$, with an overall nodule diameter of $8 \mathrm{~cm}$ ) which are relatively near to the MC criteria and lead to a projected expansion of HCC LT indications by about 5\% [37]. Retrospective and prospective analyses from UCSF and other centers showed that the survival results of MC and USCF criteria did not differ $[8,38]$. Another proposed expansion is the 'up-to-seven' classification, in which HCC is classified as the sum of the largest tumor and the number of tumor nodules. This was reported in a retrospective study on over 1,700 explants, which reported that HCC inside these criteria without microvascular inva- 


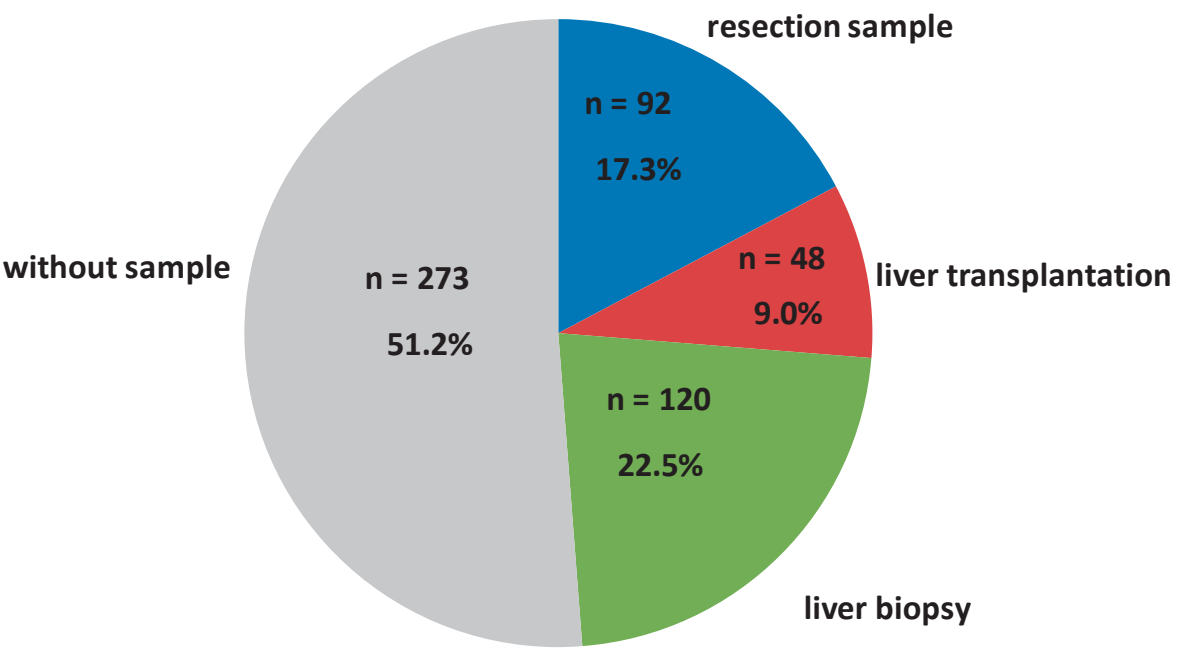

Fig. 4. Availability of histological specimens in 533 HCC patients seen at Bonn University Hospital. In about $50 \%$, no histology is available, which is largely influenced by the BCLC staging classification and recommendations.

sion had a 5-year survival comparable to that of patients inside the MC, which was also validated in a separate cohort $[39,40]$. Before these proposals are suitable for a broad implementation into clinical practice, prospective validation is required to provide detailed overall survival data including waiting list survival, the impact on waiting time, and dropout rates. With the expansions proposed to date, the 5-year survival rates would vary between 40 and $70 \%$. One of the most important prognostic factors appears to be microvascular invasion, which is likely to be more prevalent in more advanced HCC and has been shown to determine outcome after LT. Currently, histology is not routinely available or recommended before LT, and the BCLC classification relies completely on imaging modalities. Therefore, pre-LT histologic data is not available in the majority of patients. In our own experience, histology is available in under $50 \%$ of all HCC patients (fig. 4), and the samples obtained are for the most part from resection or LT specimens. Preoperative prediction by histology would be an important measure and tool for the further development of expanded LT listing criteria (see also next chapters).

The other point of contention is how to deal with patients undergoing so-called down-staging by antitumor bridging procedures [41], which have been discussed to allow for an estimation and selection of positive biological behavior indicative of a favorable post-LT prognosis. In any case, the benchmark for these considerations is to at least meet the survival of patients undergoing LT within the MC [42-44]. As a target for down-staging, again the MC have been utilized and comparable outcomes reported [42, 44]. An unresolved issue is the observation period after down-staging, which would allow for a robust assessment of tumor control and tumor biology. Whether 3 months are an acceptable interval, has not been decided. The most frequently employed down-staging procedures in the order of their frequency of application are TACE, RFA, SIRT, and surgical resection [45-50]. One of the major problems with down-staging protocols is the diversity of procedures and decision making. In most specialized hepatology and LT centers, the decision for antitumor procedures capable of down-staging is made by the local tumor board and takes into account locally available modalities and expertise, thus likely introducing a significant bias into the general validity of the obtained data. This implies that data on the inclusion or exclusion of patients from these interventions is not comparable between centers and countries, and therefore robust conclusions for the implementation of down-staging as a part of patient selection for LT are difficult to ascertain. Clearly, multicenter prospective trials are required to resolve this issue. A proposal by the EASL-EORTC (European Association for the Study of the Liver-European Organisation for Research and Treatment of Cancer) panel has suggested that patients listed for LT progressing beyond the MC should receive an attempt of downstaging by TACE or RFA while being listed as non-active, and should be reactivated after successful down-staging and a stable waiting interval of 3 months [18].

Although general practice shows that HCC patients outside the $\mathrm{MC}$ are transplanted in up to $50 \%$ according to regional and centerspecific protocols $[8,18,38,39,51-55]$, the MC are still the most robust allocation criterion and the benchmark for survival benefit assessment in HCC. Expansion has to be guided by robust data from prospective, multicenter, multinational, and validated studies in order to prevent unacceptable pressure on the donor organ pool, increased waiting time and dropout rates, competition between indications for LT, and reduced overall survival after LT. It is also important to note that patients with HCC nodules under $2 \mathrm{~cm}$ profit from other treatment modalities and should not be primarily listed for LT.

\section{Prediction of Outcome for Liver Transplantation for HCC beyond the Milan Criteria}

The assessment of prognosis in HCC and the decision for LT leading to a selection process and allocation rules ideally requires parameters capable of predicting the individual tumor biology. This is even more important when strict criteria for patient selection are questioned with the goal of expansion to those who are otherwise excluded but would have a favorable prognosis compared to those fulfilling the criteria. A desirable test would be based 
on serum-borne or histologic parameters and not only on imaging data [4]. The course and prognosis of HCC is largely dependent on histologic grading and the presence of microscopic vascular invasion. This is taken into account in Canada, where patients outside the $\mathrm{MC}$ are selected by excluding tumors with low differentiation according to histology, leading to observed survival rates comparable to those of patients undergoing LT within the MC [56]. The problem with this approach is that HCC are most often multifocal and heterogeneous, which raises concerns about the validity of a biopsy from a dominant lesion and the general validity of this approach as a pre-LT procedure [57]. Despite these limitations, the lack of histologic data in HCC (fig. 4) is a unique feature of a malignant tumor in oncologic diagnostics and therapy. It has become evident that a number of signaling pathways are relevant to the hepatocarcinogenesis and progression of HCC. These include VEGF, MAPK, PI3K/PTEN/Akt/mTOR, c-MET, IGFR, and Wnt/ $\beta$-catenin [7]. A more precise assessment of the biological behavior of HCC is likely to increase the establishment of individualized and targeted therapies. To date, the only effective targeted therapy available is sorafenib, while most other compounds for molecularly based therapeutic approaches have failed [7]. The further development of targeted therapies in addition to the prediction of biological behavior for LT will require more studies on the molecular mechanisms involved in HCC development and progression.

Presently, there is no general recommendation to perform needle aspiration biopsies before LT in HCC. Published complication rates vary from 0.75 to $13.6 \%$ [58]. These include hemorrhage in $1 / 500$ biopsies, and hospitalization and transfusion have been reported in $1 / 2,500$ to $1 / 10,000$ biopsies. Most often, the risk of needle tract-associated tumor cell seeding is mentioned as a problem (0-3\%) although it has not been shown that this impacts tumor outcome $[59,60]$. An alternative method in these patients is a laparoscopic approach to needle biopsy [58], which has been reported as a safe methodology to overcome these concerns. Further studies are needed to evaluate the pre-LT assessments of HCC also under conditions of therapeutic down-staging with this methodology.

An old marker of HCC is alfa fetoprotein (AFP). Toso et al. [61] reported in 2009 that total tumor volume and AFP levels correlated with post-LT survival, which led to a prediction score (total tumor volume $>115 \mathrm{~cm}^{3}$ or AFP $>400 \mathrm{ng} / \mathrm{ml}$ ) as the limit for LT. AFP levels $>400 \mathrm{ng} / \mathrm{ml}$ and a total tumor diameter of $>8 \mathrm{~cm}$ were found to predict HCC recurrence [62]. In a French study, the AFP level was found to predict vascular invasion and tumor differentiation [52] and correlated with HCC recurrence and death after LT ( $\log 10$ value of AFP, tumor size, and number of tumor nodules). In HCC patients outside the MC, a subgroup was identified (AFP score of 2 and AFP levels $<100 \mathrm{ng} / \mathrm{ml}$ ) that exhibited a low recurrence rate, while this rate was high for patients with a score of $>2$ and AFP $>1,000 \mathrm{ng} / \mathrm{ml}$. Another study reported that AFP levels without tumor burden were predictive [63]. Those patients with HCC and AFP levels $<15 \mathrm{ng} / \mathrm{ml}$ at LT exhibited a favorable outcome compared to the groups with $16-65 \mathrm{ng} / \mathrm{ml}, 66-320 \mathrm{ng} / \mathrm{ml}$, and $>320$ $\mathrm{ng} / \mathrm{ml}$. HCC patients outside the MC showed excellent survival if their AFP level was $<15 \mathrm{ng} / \mathrm{ml}$, and in those meeting the MC sur- vival was poor when serum AFP was $\geq 66 \mathrm{ng} / \mathrm{ml}$. These data indicate a prognostic role of serum AFP levels (most likely independent of tumor burden) for post-LT mortality in HCC patients on the waiting list, both in terms of the absolute values and the relative change. Currently, AFP is not generally used for prediction or patient selection for LT in HCC $[18,34,35]$.

\section{Allocation Principles for HCC}

Donor organs for LT are allocated following rules of prioritization, taking into account the need for transplantation and also the expected outcome. These rules have undergone changes in the course of time; they were initially based on center allocation, then employed the Child-Turcotte-Pugh score to reflect the acuity of need using waiting time on the waiting list, and finally were modified to implement the model for end-stage liver disease (MELD) score which has been used in Germany since 2006 [64]. None of these allocation principles are ideal for patients with HCC because not one reflects the risk of tumor growth during waiting time. For this reason, HCC patients are prioritized based on exceptional MELD points (standard exception (SE)) which are bound to the fulfilment of clear criteria, most notably the MC. This way, the original idea was to produce a similar waiting list mortality for HCC and non-neoplastic patients. Exception points are (re-)assigned every 3 months $[34,35]$ based on the estimation that progression of HCC can produce a $15 \%$ increase in mortality [65]. The initially suspected disadvantage of HCC patients on the waiting list was later found to represent an advantage for this patient group, and the probability of LT was higher for HCC candidates than for other patients [66], leading to a concrete disadvantage for all other LT indications [67]. As a result, SE priority in the US was modified to account for this fact, leading to two different modifications: i) For HCC nodules $<2 \mathrm{~cm}$, the initially assigned mortality of $15 \%$ (24 MELD points) was reduced to 8\% (20 MELD points) in 2003 and further reduced to $0 \%$ ( 0 MELD points) in 2004, which discourages the prioritization and listing for LT of HCC patients with small nodules of up to $2 \mathrm{~cm}$; in these patients, the risk of LT has to be weighed against the benefit of alternative treatment options including hepatic resection. ii) For patients within the MC, the initial mortality of $30 \%$ (29 MELD points) was reduced to 15\% (24 MELD points) in 2003 and further reduced to 22 MELD points in 2005. This assessment was adopted by the German allocation rules for LT in HCC and is valid until today [35].

In an attempt to develop more disease-specific allocation rules, other ideas have been pursued and reported, which take tumor burden and AFP into account. To this end, the so-called HCCMELD equation (1.27/MELD - 0.51/logAFP + 4.59) was suggested [68]. The idea was to incorporate hepatic function and AFP to more accurately describe HCC patients in an attempt to not disadvantage non-HCC patients. Another suggestion from the US and the UK includes HCC size, HCC nodule number, AFP value, and $\operatorname{MELD}(-37.8+1.9 \times \operatorname{MELD}+5.9$ (if HCC number $\geq 2)+5.9$ (if AFP level $>400 \mathrm{ng} / \mathrm{ml})+21.2($ if HCC size $>1 \mathrm{~cm}$ ) [67]. The fair 
allocation of donor organs to HCC patients continues to represent a challenge, and new models require development and prospective multicenter multinational evaluation and validation.

\section{Revision of HCC Allocation (Standard Exception) in Germany 2016}

A revision of the criteria for the allocation of HCC (SE criteria) in Germany was necessary to harmonize the existing regulations for liver allocation with current practice guidelines for HCC [69]. In addition, the definition of HCC eligible for SE priority was repeatedly subject to queries by the German transplant centers specifically regarding very small nodules under $1 \mathrm{~cm}$, transplantation of HCC patients with a single nodule under $2 \mathrm{~cm}$, and the required diagnostic modalities in this situation. All of this proceeded against the background of the so-called 'transplantation scandal' in which a broad discussion of allocation rules and their implementation led to a systematic audit of all German transplantation centers. This has led to the fundamental reformation of the process of establishing allocation rules as laid out by the TPG.

As published in February 2016, the process of establishing allocation criteria and rules has been specified and formalized [70]. In contrast to clinical practice guidelines, these rules (Richtlinien) represent mandatory operating procedures that the involved transplantation centers are legally obliged to observe and implement. The process has been modified to become more transparent and is based on expert discussions aimed at defining and employing current medical knowledge. The German Transplantation Society (DTG) as an interdisciplinary scientific body was named as partner of the German Chamber of Physicians (Bundesärztekammer $(\mathrm{BÄK}))$. Within the organ-specific working groups of the DTG, problems with allocation rules and new scientific and clinical developments of e.g. LT are discussed and positions defined and established. The actual revisions are then discussed and drafted in a working party group affiliated with the Commission for Organ Transplantation (StäKO) of the BÄK. This group consists of experts in the field and members of the DTG in addition to representatives of patient organizations, the organ procurement agency, Eurotransplant, and legal representatives. A first draft is presented to the StäKO for initial review and discussion, and, if approved, it is published on the internet for comments. After revision and consideration of comments, a second review and discussion follow. This draft is then submitted for approval to the board of the BÄK and passed on to the Federal Ministry of Health. Only after approval by the Ministry of Health it is published in the Deutsches Ärzteblatt journal and is in place and binding the day after it is published [70]. The revision format was also specified and includes a detailed account of those involved in the discussion, the time of the different meetings, and how comments were dealt with, and provides a detailed and referenced scientific explanation as well as reasons why revision was necessary [70]. This novel process takes into account the strive for a transparent and scientifically based development of allocation rules.
The following points were revised in the new version of the HCC SE [35] (effective from 17/05/2016):

Instead of a HCC definition representing a modified version of the MC, the staging criteria of the United Network for Organ Sharing (UNOS), the UNOS T criteria, were adopted because they were thought to more accurately reflect a clinically relevant tumor staging. UNOS T2 is adopted as primary indication for LT with an SE priority, which is present when 1 nodule of $>2 \mathrm{~cm}$ and $<5 \mathrm{~cm}$ or 2-3 nodules of $>1 \mathrm{~cm}$ and $<3 \mathrm{~cm}$ are present in a cirrhotic liver without extrahepatic tumor spread or macrovascular invasion. The diameter is specified as the largest diameter determined in any imaging modality employed. In cases where bridging therapy is performed, the measurements before intervention are reported and used. Patients reaching UNOS T2 after down-staging are currently excluded from SE priority. This decision was intensely debated in view of the literature regarding favorable outcomes following down-staging therapies. To address this issue, a nationwide study sponsored by BÄK is planned to provide the necessary data in the unique setting of the German transplant centers required to further develop this issue and to provide criteria for the expansion of the MC. Likewise, SE priority is not assigned to single nodules $<2 \mathrm{~cm}$. Nodules under $1 \mathrm{~cm}$ are not considered for classification at all because imaging modalities are not sensitive enough to provide a clear diagnostic assessment in these cases and distinguish them from regenerative nodules. Follow-up is required every 3 months with the best possible imaging modality.

In the past, patients who had been beyond the $\mathrm{MC}$ once never again qualified for SE priority. To address this issue, in particular when these patients e.g. achieved long-lasting remission after complete resection, the new revision classifies HCC occurring 24 months after initially achieved potentially curative local therapies or resection as a new onset of HCC and thereby potentially eligible for SE.

The diagnostic modalities were reviewed and defined according to nodule size. In HCC nodules between 1 and $2 \mathrm{~cm}, 2$ imaging studies are required (contrast MRI, contrast CT, contrast ultrasound); for nodules $>2 \mathrm{~cm}$, one imaging study (contrast MRI or contrast CT) is sufficient. The diagnosis of any sized nodule can alternatively proceed by means of biopsy and histology. Great care was taken to standardize the minimal technical requirements and reporting of these results. To this end, a list of technical requirements and the specific contrast material pattern and dynamics were specified. A standardized reporting form was developed for the initial and follow-up imaging studies. Staging for extrahepatic spread requires an abdominal MRI or CT and a chest CT scan.

Recertification intervals remained at 3 months and the assigned match MELD was also not changed for lack of specific data indicating a need for a higher or lower priority of HCC patients. This point requires future attention because it greatly influences the relative priority of HCC and non-HCC indications in LT.

At the discretion of the interdisciplinary transplant board (conference), which is mandatory in all transplant centers, consists of at least 4 members from different specialties, and is the ultimately responsible decision maker, HCC patients beyond MC can be listed 
for LT if tumor infiltration of the portal and hepatic veins is absent and extrahepatic metastases are excluded.

A new feature of the revision is the opportunity to request an external audit when a positive prognosis is likely although the allocation criteria for SE priority are not met.

The new revision has contributed to the clarification of the diagnostic modalities, has emphasized the indication for LT in single HCC nodules $>2 \mathrm{~cm}$, defines HCC nodules $>24$ months after successful local therapy as new HCC with respect to SE eligibility, and has standardized reporting and imaging requirements. The devel- opment of allocation rules is a continuous process in view of the continuing advances of the management of HCC.

\section{Disclosure Statement}

The author has no financial disclosures to declare. The author acts as chair of the Liver Allocation Rule Working Group of the Commission of Organ Transplantation (StäKO) of the German Federal Chamber of Physicians (Bundesärztekammer), and is a member of the governing board of the German Transplantation Society (DTG).

\section{References}

1 Forner A, Llovet JM, Bruix J: Hepatocellular carcinoma. Lancet 2012;379:1245-1255.

2 Bruix J, Reig M, Sherman M: Evidence-based diagnosis, staging, and treatment of patients with hepatocellular carcinoma. Gastroenterology 2016;150:835-853.

3 Llovet JM, Bustamante J, Castells A, Vilana R, Ayuso Mdel C, Sala M, Bru C, Rodes J, Bruix J: Natural history of untreated nonsurgical hepatocellular carcinoma: Rationale for the design and evaluation of therapeutic trials. Hepatology 1999;29:62-67.

4 Soriano A, Varona A, Gianchandani R, Moneva ME, Arranz J, Gonzalez A, Barrera M: Selection of patients with hepatocellular carcinoma for liver transplantation: past and future. World J Hepatol 2016;8:58-68.

5 Mazzanti R, Arena U, Tassi R: Hepatocellular carcinoma: where are we? World J Exp Med 2016;6:21-36.

6 Calle EE, Rodriguez C, Walker-Thurmond $\mathrm{K}$, Thun MJ: Overweight, obesity, and mortality from cancer in a prospectively studied cohort of U.S. adults. N Engl J Med 2003;348:1625-1638.

7 Bruix J, Han KH, Gores G, Llovet JM, Mazzaferro V: Liver cancer: approaching a personalized care. J Hepatol 2015;62:S144-156.

8 Yao FY, Ferrell L, Bass NM, Watson JJ, Bacchetti P, Venook A, Ascher NL, Roberts JP: Liver transplantation for hepatocellular carcinoma: expansion of the tumor size limits does not adversely impact survival. Hepatology 2001;33:1394-1403.

-9 Bruix J, Gores GJ, Mazzaferro V: Hepatocellular carcinoma: clinical frontiers and perspectives. Gut 2014;63: $844-855$.

10 Llovet JM, Bru C, Bruix J: Prognosis of hepatocellular carcinoma: the BCLC staging classification. Semin Liver Dis 1999; 19:329-338.

11 Saraswat VA, Pandey G, Shetty S: Treatment algorithms for managing hepatocellular carcinoma. J Clin Exp Hepatol 2014;4:S80-89.

12 Llovet JM, Fuster J, Bruix J: The Barcelona approach: diagnosis, staging, and treatment of hepatocellular carcinoma. Liver Transpl 2004;10:S115-120.

13 Pang TC, Lam VW: Surgical management of hepatocellular carcinoma. World J Hepatol 2015;7:245-252.

14 Ramesh H: Resection for hepatocellular carcinoma. J Clin Exp Hepatol 2014;4:S90-96.

15 Cucchetti A, Cescon M, Golfieri R, Piscaglia F, Renzulli M, Neri F, Cappelli A, Mazzotti F, Mosconi C, Colecchia A, Ercolani G, Pinna AD: Hepatic venous pressure gradient in the preoperative assessment of patients with resectable hepatocellular carcinoma. J Hepatol 2016;64:79-86.

16 Mazzaferro V, Chun YS, Poon RT, Schwartz ME, Yao FY, Marsh JW, Bhoori S, Lee SG: Liver transplantation for hepatocellular carcinoma. Ann Surg Oncol 2008; 15:1001-1007.
17 Kudo M, Matsui O, Izumi N, Iijima H, Kadoya M, Imai Y: Surveillance and diagnostic algorithm for hepatocellular carcinoma proposed by the liver cancer study group of japan: 2014 update. Oncology 2014;87 (suppl 1):7-21.

18 Clavien PA, Lesurtel M, Bossuyt PM, Gores GJ, Langer B, Perrier A: Recommendations for liver transplantation for hepatocellular carcinoma: an international consensus conference report. Lancet Oncol 2012;13: e11-22.

19 Bruix J, Sherman M: Management of hepatocellular carcinoma: an update. Hepatology 2011;53:1020-1022.

20 Mancuso A, Perricone G: Hepatocellular carcinoma and liver transplantation: state of the art. J Clin Transl Hepatol 2014;2:176-181.

21 Strassburg CP, Manns MP: Liver transplantation: indications and results (Article in German). Internist (Berl) 2009;50:550-560.

22 Weismuller TJ, Fikatas P, Schmidt J, Barreiros AP, Otto G, Beckebaum S, Paul A, Scherer MN, Schmidt HH, Schlitt HJ, Neuhaus P, Klempnauer J, Pratschke J, Manns MP, Strassburg CP: Multicentric evaluation of model for end-stage liver disease-based allocation and survival after liver transplantation in Germany - limitations of the 'sickest first'-concept. Transpl Int 2011; 24:91-99.

23 Weismuller TJ, Negm A, Becker T, Barg-Hock H, Klempnauer J, Manns MP, Strassburg CP: The introduction of MELD-based organ allocation impacts 3-month survival after liver transplantation by influencing pretransplant patient characteristics. Transpl Int 2009;22:970-978.

24 Gores GJ: Liver transplantation for malignant disease. Gastroenterol Clin North Am 1993;22:285-299.

25 Iwatsuki S, Starzl TE: Role of liver transplantation in the treatment of hepatocellular carcinoma. Semin Surg Oncol 1993;9:337-340.

26 McPeake JR, O’Grady JG, Zaman S, Portmann B, Wight DG, Tan KC, Calne RY, Williams R: Liver transplantation for primary hepatocellular carcinoma: tumor size and number determine outcome. J Hepatol 1993; 18:226-234.

27 Bismuth H, Chiche L: Comparison of hepatic resection and transplantation in the treatment of liver cancer. Semin Surg Oncol 1993;9:341-345.

28 Mazzaferro V, Regalia E, Doci R, Andreola S, Pulvirenti A, Bozzetti F, Montalto F, Ammatuna M, Morabito A, Gennari L: Liver transplantation for the treatment of small hepatocellular carcinomas in patients with cirrhosis. N Engl J Med 1996;334:693-699.

29 Bismuth H, Chiche L, Adam R, Castaing D, Diamond T, Dennison A: Liver resection versus transplantation for hepatocellular carcinoma in cirrhotic patients. Ann Surg 1993;218:145-151.
30 Bismuth H, Majno PE, Adam R: Liver transplantation for hepatocellular carcinoma. Semin Liver Dis 1999;19: 311-322.

31 Jonas S, Bechstein WO, Steinmuller T, Herrmann M, Radke C, Berg T, Settmacher U, Neuhaus P: Vascular invasion and histopathologic grading determine outcome after liver transplantation for hepatocellular carcinoma in cirrhosis. Hepatology 2001;33:1080-1086.

32 Llovet JM, Fuster J, Bruix J: Intention-to-treat analysis of surgical treatment for early hepatocellular carcinoma: resection versus transplantation. Hepatology 1999;30:1434-1440.

33 Mazzaferro V, Bhoori S, Sposito C, Bongini M, Langer M, Miceli R, Mariani L: Milan criteria in liver transplantation for hepatocellular carcinoma: an evidencebased analysis of 15 years of experience. Liver Transpl 2011;17(suppl 2):S44-57.

34 Rahimi RS, Trotter JF: Liver transplantation for hepatocellular carcinoma: outcomes and treatment options for recurrence. Ann Gastroenterol 2015;28:323-330.

35 Bundesärztekammer: Richtlinien zur Organtransplantation gem. \$16 TPG. Deutsch Arztebl 2016;A1-A22.

36 Mancuso A: Management of hepatocellular carcinoma: enlightening the gray zones. World J Hepatol 2013;5: 302-310.

37 Prasad KR, Young RS, Burra P, Zheng SS, Mazzaferro V, Moon DB, Freeman RB: Summary of candidate selection and expanded criteria for liver transplantation for hepatocellular carcinoma: a review and consensus statement. Liver Transpl 2011;17(suppl 2):S81-89.

38 Yao FY, Xiao L, Bass NM, Kerlan R, Ascher NL, Roberts JP: Liver transplantation for hepatocellular carcinoma: validation of the UCSF-expanded criteria based on preoperative imaging. Am J Transplant 2007;7: 2587-2596.

39 Mazzaferro V, Llovet JM, Miceli R, et al: Predicting survival after liver transplantation in patients with hepatocellular carcinoma beyond the Milan criteria: a retrospective, exploratory analysis. Lancet Oncol 2009; 10:35-43.

40 Raj A, McCall J, Gane E: Validation of the 'Metroticket' predictor in a cohort of patients transplanted for predominantly HBV-related hepatocellular carcinoma. J Hepatol 2011;55:1063-1068.

41 Prasad MA, Kulik LM: The role of bridge therapy prior to orthotopic liver transplantation. J Natl Compr Canc Netw 2014;12:1183-1190, quiz 1191.

42 Clavien PA, Kang KJ, Selzner N, Morse MA, Suhocki PV: Cryosurgery after chemoembolization for hepatocellular carcinoma in patients with cirrhosis. J Gastrointest 2002;6:95-101. 
43 Pomfret EA, Washburn K, Wald C, Nalesnik MA, Douglas D, Russo M, Roberts J, Reich DJ, Schwartz ME, Mieles L, Lee FT, Florman S, Yao F, Harper A, Edwards E, Freeman R, Lake J: Report of a national conference on liver allocation in patients with hepatocellular carcinoma in the united states. Liver Transpl 2010;16:262-278.

44 Yao FY, Breitenstein S, Broelsch CE, Dufour JF, Sherman M: Does a patient qualify for liver transplantation after the down-staging of hepatocellular carcinoma? Liver Transpl 2011;17(suppl 2):S109-116.

45 Decaens T, Roudot-Thoraval F, Bresson-Hadni S, Meyer C, Gugenheim J, Durand F, Bernard PH, Boillot O, Boudjema K, Calmus Y, Hardwigsen J, Ducerf C, Pageaux GP, Dharancy S, Chazouilleres O, Dhumeaux D, Cherqui D, Duvoux C: Impact of pretransplantation transarterial chemoembolization on survival and recurrence after liver transplantation for hepatocellular carcinoma. Liver Transpl 2005;11:767-775.

46 Llovet JM, Mas X, Aponte JJ, Fuster J, Navasa M, Christensen E, Rodes J, Bruix J: Cost effectiveness of adjuvant therapy for hepatocellular carcinoma during the waiting list for liver transplantation. Gut 2002;50: 123-128.

47 Lu DS, Yu NC, Raman SS, Lassman C, Tong MJ, Britten C, Durazo F, Saab S, Han S, Finn R, Hiatt JR, Busuttil RW: Percutaneous radiofrequency ablation of hepatocellular carcinoma as a bridge to liver transplantation. Hepatology 2005;41:1130-1137.

48 Majno PE, Adam R, Bismuth H, Castaing D, Ariche A, Krissat J, Perrin H, Azoulay D: Influence of preoperative transarterial lipiodol chemoembolization on resection and transplantation for hepatocellular carcinoma in patients with cirrhosis. Ann Surg 1997;226:688-701, discussion 701-703.

49 Mazzaferro V, Battiston C, Perrone S, Pulvirenti A, Regalia E, Romito R, Sarli D, Schiavo M, Garbagnati F, Marchiano A, Spreafico C, Camerini T, Mariani L, Miceli R, Andreola S: Radiofrequency ablation of small hepatocellular carcinoma in cirrhotic patients awaiting liver transplantation: a prospective study. Ann Surg 2004;240:900-909.

50 Porrett PM, Peterman H, Rosen M, Sonnad S, Soulen M, Markmann JF, Shaked A, Furth E, Reddy KR Olthoff K: Lack of benefit of pre-transplant locoregional hepatic therapy for hepatocellular cancer in the current meld era. Liver Transpl 2006;12:665-673.
51 De Carlis L, Di Sandro S, Giacomoni A, Slim A, Lauterio A, Mangoni I, Mihaylov P, Pirotta V, Aseni P, Rampoldi A: Beyond the Milan criteria: what risks for patients with hepatocellular carcinoma progression before liver transplantation? J Clin Gastroenterol 2012; 46:78-86.

52 Duvoux C, Roudot-Thoraval F, Decaens T, et al: Liver transplantation for hepatocellular carcinoma: a model including alpha-fetoprotein improves the performance of Milan criteria. Gastroenterology 2012;143:986-994. e983, quiz e914-985.

53 Mela M, Mancuso A, Burroughs AK: Review article: hepatocellular carcinoma: Indications for liver transplantation. Aliment Pharmacol Ther 2003;17(suppl 2):130-137.

54 Ravaioli M, Grazi GL, Piscaglia F, Trevisani F, Cescon M, Ercolani G, Vivarelli M, Golfieri R, D’Errico Grigioni A, Panzini I, Morelli C, Bernardi M, Bolondi L, Pinna AD: Liver transplantation for hepatocellular carcinoma: results of down-staging in patients initially outside the Milan selection criteria. Am J Transplant 2008;8:2547-2557.

55 Yao FY, Kerlan RK Jr, Hirose R, Davern TJ 3rd, Bass NM, Feng S, Peters M, Terrault N, Freise CE, Ascher NL, Roberts JP: Excellent outcome following downstaging of hepatocellular carcinoma prior to liver transplantation: an intention-to-treat analysis. Hepatology 2008;48:819-827.

56 DuBay D, Sandroussi C, Sandhu L, Cleary S, Guba M, Cattral MS, McGilvray I, Ghanekar A, Selzner M, Greig PD, Grant DR: Liver transplantation for advanced hepatocellular carcinoma using poor tumor differentiation on biopsy as an exclusion criterion. Ann Surg 2011;253:166-172.

57 Young RS, Aldiwani M, Hakeem AR, Nair A, Guthrie A, Wyatt J, Treanor D, Morris-Stiff G, Jones RL, Prasad KR: Pre-liver transplant biopsy in hepatocellular carcinoma: a potential criterion for exclusion from transplantation? HPB (Oxford) 2013;15:418-427.

58 Strassburg CP, Manns MP: Approaches to liver biopsy techniques - revisited. Semin Liver Dis 2006;26:318327.

59 Colecchia A, Schiumerini R, Cucchetti A, Cescon M, Taddia M, Marasco G, Festi D: Prognostic factors for hepatocellular carcinoma recurrence. World J Gastroenterol 2014;20:5935-5950.
60 Durand F, Belghiti J, Paradis V: Liver transplantation for hepatocellular carcinoma: role of biopsy. Liver Transpl 2007;13:S17-23.

61 Toso C, Asthana S, Bigam DL, Shapiro AM, Kneteman NM: Reassessing selection criteria prior to liver transplantation for hepatocellular carcinoma utilizing the scientific registry of transplant recipients database. Hepatology 2009;49:832-838.

62 Lai Q, Avolio AW, Manzia TM, Sorge R, Agnes S, Tisone G, Berloco PB, Rossi M: Combination of biologi$\mathrm{cal}$ and morphological parameters for the selection of patients with hepatocellular carcinoma waiting for liver transplantation. Clin Transplant 2012;26:E125131.

63 Berry K, Ioannou GN: Serum alpha-fetoprotein level independently predicts posttransplant survival in patients with hepatocellular carcinoma. Liver Transpl 2013;19:634-645.

64 Strassburg CP: Patient selection and indications for liver transplantation (Article in German). Der Chirurg 2013;84:363-371.

65 Freeman RB, Jamieson N, Schaubel DE, Porte RJ, Villamil FG: Who should get a liver graft? J Hepatol 2009; 50:664-673.

66 Washburn K, Edwards E, Harper A, Freeman R: Hepatocellular carcinoma patients are advantaged in the current liver transplant allocation system. Am J Transplant 2010;10:1643-1648

67 Toso C, Majno P, Berney T, Morel P, Mentha G, Combescure C: Validation of a dropout assessment model of candidates with/without hepatocellular carcinoma on a common liver transplant waiting list. Transpl Int 2014;27:686-695.

68 Vitale A, Volk ML, De Feo TM, Burra P, Frigo AC, Ramirez Morales R, De Carlis L, Belli L, Colledan M, Fagiuoli S, Rossi G, Andorno E, Baccarani U, Regalia E, Vivarelli M, Donataccio M, Cillo U: A method for establishing allocation equity among patients with and without hepatocellular carcinoma on a common liver transplant waiting list. J Hepatol 2014;60:290-297.

69 Greten TF, Malek NP, Schmidt S, et al: Diagnosis of and therapy for hepatocellular carcinoma (Article in German). Z Gastroenterol 2013;51:1269-1326.

70 Bundesärztekammer: Richtlinien zur Organtransplantation gem. \$16 TPG - Verfahrensordnung der Ständigen Kommission Organtransplantation (VerfOStäKO). Dtsch Arztebl 2016;8:A346-A348. 